\title{
Chagas disease: still a challenge around the World
}

\author{
João Carlos Pinto Dias ${ }^{[1]}$
}

[1]. Emeritus Researcher, Centro de Pesquisas René Rachou, Fundação Oswaldo Cruz, Belo Horizonte, Minas Gerais, Brasil.

\section{Introduction}

Very early in the history of human Chagas disease (HCD), the discoverer called upon scientists and governments to take responsibility for facing its medical and social consequences. It was an almost insurmountable task, since effective insecticides and drugs for medical treatment were not available at that time, and HCD was not recognized by the scientific community. Before his death in 1934, Carlos Chagas could not see anyone paying attention to his appeals. Nevertheless, a new era arose from his ideas that were taken up by his disciples and scientific followers ${ }^{(1)(2)(3)(4)}$.

\section{Visibility of disease over time}

Human Chagas disease began to be accepted as a major health problem since the description of Romaña's sign (1935), which provided a method for the detection of hundreds of acute cases in several countries. Other historic achievements were ${ }^{(1)(3)}$ :

- Improvement of serological diagnosis (complement fixation testing, 1940s), followed by hemmaglutination and immunofluorescence tests (1960s).

- Serological screenings in endemic areas since 1946, shortly thereafter accompanied by electrocardiographic surveys.

- $\quad$ Serological screening in blood banks since 1949.

- Systematization of chronic heart disease in 1956.

- Description of the digestive form of the disease in 1955.

- The founding of international congresses and meetings on HCD in 1959 (Rio), 1960 (Washington), 1970 (Caracas), 1975 (Belo Horizonte), and 1979 (Rio).

- The emergence of agencies supporting researches on HCD in the 1970s, such as the Latin American research councils and the Tropical Disease Research program of the World Health Organization.

- National serological surveys of vector distribution and disease prevalence. In 1980, the prevalence in Brazil was estimated at 5 million individuals, with an incidence rate of 100,000 new cases annually, with chronic cardiomyopathy affecting $25-30 \%$ of the infected people. Such results became important arguments to increase the priority for a national control program.

Corresponding author: Dr. João Carlos Pinto Dias. CPqRR/FIOCRUZ. Av. Augusto de Lima 1715, Barro Preto, 30190-002, Belo Horizonte, Minas Gerais, Brasil.

Phone: 5531 3349-7760

e-mail: jcpdias@cpqrr.fiocruz.br

Received 30 July 2015

Accepted 4 August 2015

\section{Facing Human Chagas disease}

Underdevelopment and the lack of political priority have been the major constraints on the fight against HCD. In the 1970s, mathematical models indicated that the social development of endemic regions would be sufficient for the prevention of vector transmission, a solution that was extremely difficult to be implemented in poor countries, at short time. Without specific actions, transmission would continue for decades. As an alternative, the control of domestic vectors and blood banks were implemented in some countries ${ }^{(1)(5)}$.

Gamma-hexachlorocyclohexane was the most widely used insecticide until the late 1970s, when it began to be replaced by synthetic pyrethroids $^{(3)}{ }^{(4)}$. Specific treatment was developed in the 1960s, with the successful use of nifurtimox in acute cases of HCD. Meanwhile, the medical importance of HCD was progressively being recognized, driving the implementation of control programs based on chemical vector control and housing improvements. Blood bank control became widely implemented in the 1980s, following the emergence of AIDS and the diffusion of modern serological techniques. In 1991, a very new and politically important fact was the launching of the Intergovernmental Initiatives to join international efforts and capabilities together for disease control ${ }^{(1)(2)(5)(6)}$.

\section{Present situation and future}

Stringent control measures have largely reduced HCD transmission over a wide endemic region, with infection becoming concentrated in higher age groups. However, active transmission remains in some poor and ecologically complicated regions. Major problems have been the maintenance of vector surveillance, new epidemiological situations (sylvatic and secondary vectors, oral transmission, insecticide resistance, urbanization and migration of infected individuals), political constraints (instability, decentralization of health programs), and the existing millions of cases requiring medical attention. Realistic programs undertaken to address HCD must continue to be implemented and improved, taking into account the challenges expected when moving forward ${ }^{(3)(5)(6)(7)}$.

\section{Managing the disease}

In practice, infected individuals are of low socioeconomic standing and illiterate, and are dependent on aid from public health systems to provide a diagnosis, access to treatment, expertise, and drugs. Cases of HCD should be handled at different health care levels, since early diagnosis and correct management is the best way to ensure a positive outcome for patients ${ }^{(5)(8)(9)}$. Nevertheless, the limitations on diagnostic opportunities are remarkable, mainly 
due to low symptomatology, incorrect diagnosis by physicians, and the lack of regional laboratories.

It is unrealistic to hope that HCD will be treated by specialists in poor countries. General clinicians should be able to treat the majority of patients, who generally are in the indeterminate or initial chronic forms. A secondary level of health care is required in strategic areas, to provide adequate diagnoses and complex interventions. About 3-5\% of cases will require tertiary level care, with higher medical expertise and hospital facilities, involving high costs and problems of access. Millions of infected people will require specific and symptomatic treatments in Latin America and the rest of the world over the next 30 years, but the proportion of detected and treated cases has been extremely low. Better drugs for specific treatment are highly desirable, but new products usually take years to be available and the benefits of the treatment generally diminish with the duration of infection $^{(5)(8)(9)(10)}$. Benznidazole and nifurtimox must continue to be the mainstay of treatment, but their production today is not a priority of the existing manufacturers ${ }^{(10)}$. Symptomatic treatment has advanced greatly in terms of heart and digestive tract symptom management, but its provision is also extremely low in terms of the real need ${ }^{(5)(8)}$.

In short, political will and permanent advocacy are also required, to face the costs, the coverage and the sustainability of preventative actions and medical attention for HCD, all over the world.

\section{Human Chagas disease in 2015}

The incidence and social impact of HCD have significantly decreased since the beginning of the 21 st century, compared to previous decades. The driving factors behind this change are of a social nature (e.g., urbanization, improved living standards, modernization of agriculture) which complement specific interventions (e.g., vector and blood bank control, and better conditions for medical care). A new scenery of Chagas disease programs is replacing the classical vertical approach, moving towards decentralized models. In the 1990s, globalization and market-controlled economies imposed the policy to deliver resources and responsibilities to the periphery, in order to minimize central and national structures. Nevertheless, in poor endemic regions, the transition to decentralization is difficult, since low-income municipalities do not have the sufficient expertise, organization, and political will to face $\mathrm{HCD}^{(2)(5)(7)}$. New epidemiological situations have been observed in the last years. Triatoma infestans was eliminated in large geographic areas, but remains the focus in the Chaco region, with a similar situation existing in South and Central America for Rhodnius prolixus. Fortunately, it appears that the Amazon region will not be invaded and colonized by allochthonous species such as Triatoma brasiliensis, Triatoma dimidiata, and Panstrongylus megistus, and the encroaching of native species into human homes will remain very $\operatorname{rare}^{(2)(3)(7)}$. Pyrethroids still are fast-acting for vector control, but new products and formulations are required in an attempt to find a more consistent residual effect. Native wild species naturally persist, but their domestic density is hardly noticeable when control activities are maintained. Regional laboratories able to monitor triatomine populations and insecticide resistance are required. The progressive modernization of rural activities and living standards are also contributing to the reduction of vector domiciliation, but attention must be paid to the peridomestic environment $^{(3)(6)}$. The greatest challenges in vector control are undoubtedly the dismantling of regular programs, mainly due to untimely decentralization, and the move away from HCD as a priority goal. Technical regional structures are required to warrant continuity of activities at the peripheral level. Since blood banks are being controlled in endemic countries, it is anticipated that in the next 20 years, only exceptional cases of blood-based HCD transmission will occur. A similar trend is also anticipated for congenital transmission, since the younger generations of women in endemic areas are becoming free from Trypanosoma cruzi infection ${ }^{(2)(6)}$. The prevalence of HCD is expected to decrease progressively in the next three decades, along with the incidence and morbidity, particular if medical care and specific treatment can be universalized. Millions of individuals are waiting for this ${ }^{(9)(10)}$. We are now at a crossroads regarding Chagas disease research, and tension is mounting due to opposing views among researchers, health authorities, and policy makers.

\section{Final remarks}

Advances in disease control, diagnosis, and clinical attention have led to much better management, and to a progressive awareness that transmission can be halted and the clinical course of the infection attenuated, often depending on public health organizations. Transfusion and congenital transmission are decreasing and are expected to disappear in the next 20 or 30 years, but vector control must be maintained in endemic areas, largely depending on epidemiological surveillance. Oral transmission will likely continue to appear in outbreaks, which may be managed in a focalized manner. Infected individuals will remain in higher age groups. Excessive optimism, social problems (under-employment, illiteracy, and violence), the global market, and competition with dengue, human immunodeficiency virus/acquired immunodeficiency syndrome (HIV/AIDS), and degenerative diseases have the potential to decrease the priority and the resources available to face HCD. As a whole, the great challenge now is to maintain HCD control in the government and academic agendas for the next two to three decades.

\section{CONFLICT OF INTEREST}

The authors declare that there is no conflict of interest.

\section{REFERENCES}

1. Dias JCP, Schofield CJ. The evolution of Chagas disease (American Trypanosomiasis) control after 90 years since Carlos Chagas discovery. Mem Inst Oswaldo Cruz 1999; 94:103-122.

2. Coura JR, Dias JCP. Epidemiology, control and surveillance of Chagas disease-100 years after its discovery. Mem Inst Oswaldo Cruz 2009; 104 (suppl I):31-40. 
3. Coura JR, Albajar-Viñas P, Junqueira ACV. Ecoepidemiology, short history and control of Chagas disease in the endemic countries and the new challenge for non-endemic countries. Mem Inst Oswaldo Cruz 2014; 109:856-862.

4. Dias E. Profilaxia da doença de Chagas. O Hospital 1957; 51:53-68.

5. Dias JCP, Prata A, Correa D. Problems and perspectives for Chagas disease control: in search of a realistic analysis, Rev Soc Bras Med Trop 2008; 48:193-196.

6. Ministério da Saúde. Consenso Brasileiro sobre a doença de Chagas. Rev Soc Bras Med Trop 2005; 38 (supl III):1-39.
7. Sociedade Brasileira de Cardiologia. I Diretriz Latino-Americana para o diagnóstico e tratamento da cardiopatia chagásica. Arq Bras Cardiol 2011; 96 (supl I):1-47.

8. Rassi Jr. A, Dias JCP, Marin-Neto JA, Rassi A. Challenges and opportunities for primary, secondary, and tertiary prevention of Chagas' disease. Heart 2009; 95:524-531.

9. Junqueira Jr LF. Challenges for improving quality of life in Chagas disease. Rev Soc Bras Med Trop 2015; 48:117-120.

10. Albajar-Viñas P, Dias JCP. Advancing the treatment of Chagas' disease. N Engl Med 2014; 370:1942-1943. 